\title{
Bullying and Discrimination Experiences among Korean-American Junior High
}

\section{School Students}

\author{
Thomas DiBlasi ${ }^{1 *}$, Jin Y. Shin ${ }^{1} \&$ Charles A. Dill ${ }^{1}$ \\ ${ }^{1}$ Department of Psychology, Hofstra University, Hempstead, U.S.A.
}

Received 12.05.2018; Received revised 17.10.2018; Accepted 24.10.2018

Available online 31.12.2018

\begin{abstract}
The incidence of bullying experiences has increased dramatically in recent decades and with little research on Korean-Americans. The goal of this study was to examine the experiences of six to eight grade Korean-Americans and to explore the relationships between bullying, discrimination, depression, and ethnic composition of the school, as set forth by Shin, D'Antonio, Son, Kim, and Park (2011). Path analyses for the victims, bystanders, bullies, and bully-victim combination, respectively, revealed several key findings and differences between middle school and high school. Taken together with Shin et al. (2011), these results suggest that as adolescents grow older, the ethnicity of the individuals or the ethnic composition of the schools may be more influential in the bullying experience.
\end{abstract}

Keywords: bullying, depression, Korean-American adolescents, adolescence.

Address of correspondence: Thomas DiBlasi, Department of Psychology, Hofstra University, Hempstead, NY 11549, U.S.A.

E-mail: Thomas.A.DiBlasi@hofstra.edu

\section{Introduction}

Bullying can affect anyone, and most individuals have been involved in bullying, either as a victim, bully, bystander or some combination of the three. Bullying is defined as an imbalance of power and intentional and repetitive acts that are involved in interpersonal aggression (Olweus, 1993; Smith \& Morita, 1999). Bullying can occur many different ways: physically, verbally, psychologically, and electronically (cyber bullying). The prevalence rates for victims are as little as $10 \%$ to as much as $70 \%$, with as little as $5 \%$ to as much as $13 \%$ reported bullying others (Kessel Schneider, O'Donnell, Stueve, \& Coulter, 2012; Nansel et al., 2001; Perkins, Craig, \& Perkins, 2011; Peskin, Tortolero, \& Markham, 2006; U.S. Department of Education, 1999). Additionally, more people are involved as bystanders than as victims. Studies have found that $85 \%$ to $88 \%$ of bullying events involved two to four bystanders (O'Connell, Pepler, \& Craig, 1999).

Negative effects of bullying

Bullying can lead to negative effects for everyone involved. Victims generally report more internalizing symptoms, such as loneliness and withdrawal (Graham \& Juvonen, 1998a; Kaltiala-Heino, Rimpelä, Marttunen, Rimpelä, \& Rantanen, 1999), psychosomatic complaints, anxiety, depression (Kaltiala-Heino, Rimpela, Rantanen, \& Rimpela, 2000), and suicidal ideation (Bonanno \& Hymel, 2010; Kaltiala-Heino et al., 1999). In addition, they report worse physical health (Gini \& Pozzoli, 2013; Knack, Jensen-Campbell, \& Baum, 2001), are aggressive (Hanish \& Guerra, 2000), and have academic problems, such as: truancy, performing poorly, feeling unsafe, delinquency, and even drop out of school (Juvonen, Nishina, \& Graham, 2000; Smith, Talamelli, Cowie, Naylor, \& Chauhan, 2004).

Bystanders are also at risk for negative consequences; however, there is contrasting literature on the severity of the negative outcomes on bystanders. Juvonen, Graham, and Schuster (2003) report that those who were "uninvolved" did not report loneliness, social anxiety, nor depression to the same extent as victims or bully-victims. A possible moderating factor could be the type of bystander, as discussed by Salmivalli, Lagerspetz, Björkqvist, Österman, and Kaukianinen (1996). There are those who join the bully in making fun of the victim ("assistants"), those who offer positive reinforcement to the bullies, such as laughing ("reinforcers"), those who do not get involve and observe from a distance ("outsiders"), and those who intervene in favor of the victim ("defenders"). There are potentially different consequences for each type of bystander, which could explain Rivers, Poteat, Noret, and Ashurt's (2009) 
findings. Rivers et al. (2009) reported that bystanders actually experienced more mental health concerns than that of bullies and victims. The bystanders in Rivers et al. (2009) might have been assistants instead of outsiders, which could have brought about negative effects. Participants reported symptoms such as anxiety, paranoid ideation, and obsessive-compulsiveness, and depression.

The negative effects for bullies are also unclear. Bullies report externalizing symptoms, such as conduct problems, academic challenges, aggressiveness, attention difficulties, and increased likelihood to use drugs and alcohol (Ericson, 2001). They also show internalizing symptoms including eating disorders, anxiety, psychosomatic disorders, depression, and suicidal ideation (Cook, Williams, Guerra, Kim, \& Sadek, 2010; Espelage \& Holt, 2001; Kaltiala-Heino et al., 2000; Kumpulainen et al., 1998; Kumpulainen \& Räsänen, 2000; Kumpulainen, Räsänen, \& Henttonen, 1999; Roland, 2002; Sourander, Helstelä, Helenius, \& Piha, 2000).

Bully-victims may be the most at risk of all four groups, as they most likely to experience externalizing and/or internalizing symptoms. These symptoms include somatic complaints, physical injury, anxiety, increased possibility of being referred for a psychiatric assessment, depression, low self-esteem, and issues at school, such as: absenteeism, school feeling unsafe negative attitudes toward school, and delinquency. They are also more atrisk to engage in risky behaviors such as substance abuse, aggression, self-harm, and suicidal ideation (Berkowitz \& Benbenishty, 2012; Kumpulainen et al., 2001; Nansel et al., 2001; Srabstein \& Piazza, 2013; Swearer, Song, Cary, Eagle, \& Mickelson, 2001).

\section{Bullying in Asian-Americans}

The majority of studies have used Caucasian-American samples when examining bullying, which contributes to the data being inconclusive for the prevalence rates based on ethnicity. Peskin, Tortolero, and Markham (2006) found that Blacks are more likely than Hispanics to bully and victimize. However, Peskin, Tortolero, Markham, Addy, and Baulmer (2007) found that Blacks compared to Hispanics were not more likely to be victims, nor bullies. Prevalence rates for Asian Americans are more consistent. Mouttapa, Valente, Gallaher, Rohrbach and Unger (2004) had an ethnically diverse sample and found that AsianAmericans were most likely to be the victimized ethnic group. Surprisingly, Asian-Americans recorded more victimization even after controlling for Asian-Americans being majority or minority ethnic group. While Moran, Smith, Thompson, and Whitney (1993) found that there were no differences in victimization or bullying for Asian and White children, aged nine to fifteen, they, along with Boulton (1995), found that Asians were more likely to be the target of racist name calling. This discrimination is related to a list of negative side effects for AsianAmericans, including: distress, depression, and alienation from peers (Grossman, 2005; Liang, Grossman, \& Deguchi, 2007; Qin, Way, \& Mukherjee, 2008).

While Asian-Americans are a leading target for bullying and discrimination (Mouttapa et al., 2004), there are some groups of Asian-Americans that are more vulnerable (e.g., Korean-American youth; Uba, 1994). Kuo (1984) found that Korean-American adults were much more likely to report depressive symptoms than PhilippineAmericans, Japanese-Americans, and Chinese-Americans. This high depression prevalence rate has been replicated for Korean-American adolescents (Hovey, Kim, \& Seligman, 2006; Kim \& Cain, 2008).

Several studies have found that increased acculturative stress is associated with increased depression for KoreanAmericans (Choi, 1997; Kuo \& Tsai, 1986; Oh, Koeske, \& Sales, 2002; Shin, 1994). This is further enhanced by the fact that there is a wide cultural gap between foreign-born parents who hold onto traditional values and the U.S. born or U.S.-raised adolescents who have more mainstream values (Lee, 1997; Rhee, 1996; Ying, 1998). Hovey et al. (2006), in line with Aldwin and Greenberger (1987) investigated further and found that those who had stronger Asian cultural ties were more likely to have lower selfesteem, depression, and anxiety. In fact, Oh et al. (2002) found the opposite of Hovey et al. (2006); KoreanAmericans who gave up their Korean values and traditions were more likely to report depressive symptoms. A possible reason for these findings could be that there is a lot of stress to balance keeping one's culture, as well as assimilating into a new culture, which causes acculturation dissonance. If that is the case, it is not a matter of keeping one's values or having new one's but rather the debate that goes along with it. One can suspect, that seeing as KoreanAmericans report more depressive symptoms than other Asian-American groups (Kuo, 1984), they may be struggling more with acculturation dissonance. Immigrants or children of immigrants are prone to acculturation dissonance, which could bring about mental health problems, language barriers, racism, and separation from family (Sue, 1994). While all immigrant groups are at risk for these negative outcomes, Korean-Americans may be more prone to negative mental health outcomes. The bullying experience, regardless of role, may relate to Korean-Americans feeling discriminated against and depressed.

\section{Hypotheses}

There are two objectives of this study with the first one being to examine if Korean-American victims feel more depressed and discriminated against compared to nonvictims. As supported by previous literature, those who are victims are hypothesized to report higher levels of depression and discrimination of the four groups (i.e., victims, bystanders, bullies, and bully-victims; Shin et al., 2011; Shrake \& Rhee, 2004), with bystanders reporting the least amount of depression and discrimination. It was hypothesized that bullies and bully-victims would also report higher levels of depression than non-bullies and non-bully-victims, as per Shin et al. (2011). The second objective was to explore the model set forth by Shin et al. (2011) related to participants' experiences of discrimination. Discrimination was broken down to four components: unfair treatment, positive stereotypes, negative stereotypes, and discomfort. The path analyses were exploratory regarding the relationships between unfair treatment, positive stereotypes, negative stereotypes, discomfort, white composition at school, and the bullying experience.

\section{Method}

\section{Participants}

Participants consisted of 125 (57 male and 67 female) Korean-American students from middle schools in New Jersey and New York. The age range was between 10 to14 years old $(\mathrm{M}=12.5, \mathrm{SD}=1.0)$ with $60.5 \%$ of the participants 
born in the U.S. Most participants (82\%) lived with both parents, followed by $5.6 \%$ living with only mothers, $0.8 \%$ with only fathers, and $4.8 \%$ with others. The Bully Survey (Swearer 2005) was used to categorize the participants based on their responses. Participants were classified as victims $(n=51,42.9 \%)$ if they completed the section on being bullied; participants were classified as bystanders $(\mathrm{n}=91,72.8 \%)$ if they completed the section on observing others being bullied; participants were classified as bullies $(n=39,32.5 \%)$ if they completed the section on bullying others, and participants were classified as bully-victims $(n=24,19.2 \%)$ if they completed both sections on being bullied and bullying others. Participants could be classified into multiple categories.

\section{Measures}

The Bully Survey (Swearer, 2005) is a self-report survey intended to measure three components of bullying: being bullied, observing others being bullied, and bullying others. Participants can be classified as bullies, bystanders, victims, bully-victims, or uninvolved depending on their responses. Every section starts with a screening question to decide if a participant has ever been bullied, observed bullying, or bullied others in the past school year. The section is omitted if the response is "no." If the response is "yes," there are follow-up questions in regard to the type of bullying (verbal or physical), where the bullying took place, who the bullies were or who they bullied (older/younger, male/female), why they were bullied or bullied others, how bullying affected them, and if adults were aware about the bullying.

The Center for Epidemiological Studies Depression Scale (CES-D; Radloff, 1977) is a self-report measure designed to assess somatic issues, mood, interaction with others, and physical functioning during the past week. Participants rate each item between zero and four. Zero indicates less than one day during the past week and three indicates five to seven days during the past week. A total of 16 or higher on the scale generally indicates that the participant is within the clinical range of depression. According to Noh, Avison, and Kasper (1992), the CES-D has shown construct and concurrent validity in a Korean sample. The reliability for the study was excellent, $\alpha=.91$.

The Perceived Ethnic and Racial Discrimination Scale (Way, 1997) is a self-report measure designed to assess perceived discrimination from peers based on one's race or ethnicity. Participants rate items on a 5-point scale from never to always. The questionnaire consists of questions like "How often do you feel that other students in school make fun of you because of your race or ethnicity?" and "How often do other students treat you unfairly because of your race or ethnicity?" Shin et al. (2011) conducted exploratory factor analyses on the scale to determine the factor structure. Results showed that a four-factor model was most meaningfully interpretable. The factors were established using Shin et al.'s (2011) study. The first factor with high loadings from 9 items was defined as "unfair treatment," and had an alpha coefficient of .92. The second factor with high loadings from 3 items was defined as "positive stereotype," and had an alpha coefficient of .90. The third factor with high loadings from 4 items was defined as "negative stereotype," and had an alpha coefficient of .79. Lastly, the fourth factor with high loadings from 5 items was defined as "discomfort," and had an alpha coefficient of 87 .

The Report Card was found on the websites of the State Departments of Education of New Jersey (New
Jersey Department of Education, 2008) and New York (NYSTART, 2007) in order to examine the ethnic composition of different schools which participants were enrolled.

Demographic information was collected by inquiring the age, grade, the school in which they were enrolled, if they were born in the U.S, and family composition.

\section{Procedure}

Recruitment took place through various KoreanAmerican organizations such as agencies, churches, and internet networks. Participants were excluded from the study if they completed the surveys but left some of the questions unanswered, leaving a sample size of 423. For the current study, only the data from the students in grades six to eight $(n=125)$ were used. The study protocol was approved by the IRB of Hofstra University.

\section{Results}

Among the 119 participants who answered, 51 participants $(42.9 \%)$ reported experiences of being bullied, $91(72.8 \%)$ reported observing others being bullied, 39 $(32.5 \%)$ reported bullying others and $24(19.2 \%)$ reported both being bullied and bullying others. Compared to the results found by Shin et al. (2011), a chi square revealed that Korean-American students in junior high are more likely to be bullied than Korean-American students in high school, $\chi^{2}(414,1)=7.19, p=.007$. There were no significant differences by school level for bystanders $\left(\chi^{2}\right.$ $(414,1)=.163, p=.687$. There were also no significant differences by school level for bullies $\chi^{2}(414,1)=.061, p=$ .805 , nor bully-victims $\chi^{2}(414,1)=1.071, p=.301$.

Table 1. Most frequent contexts where Bullying experience occurred

\begin{tabular}{lccc}
\hline Location & $\begin{array}{l}\text { Was } \\
\text { Victimized }\end{array}$ & $\begin{array}{l}\text { Observed } \\
\text { Bullying }\end{array}$ & $\begin{array}{l}\text { Bullied } \\
\text { Others }\end{array}$ \\
\hline Cafeteria & $37.8 \%$ & $62.2 \%$ & $48.7 \%$ \\
After school & $35.6 \%$ & $47.8 \%$ & $43.2 \%$ \\
Homeroom & $33.3 \%$ & $39.8 \%$ & $27 \%$ \\
In Class & $26.7 \%$ & $31.6 \%$ & $35.1 \%$ \\
Hallway & $24.4 \%$ & $65.3 \%$ & $24.4 \%$ \\
Bus & $24.4 \%$ & $31.6 \%$ & $16.2 \%$ \\
Online/text messaging & $22.2 \%$ & $26.5 \%$ & $16.2 \%$ \\
Gym & $15.6 \%$ & $40.8 \%$ & $29.7 \%$ \\
Before school & $13.3 \%$ & $29.6 \%$ & $8.1 \%$ \\
Sporting events & $11.1 \%$ & $22.5 \%$ & $16.2 \%$ \\
Bathroom & $4.4 \%$ & $20.4 \%$ & $8.1 \%$ \\
Dances & $2.2 \%$ & $16.3 \%$ & $5.4 \%$ \\
\hline
\end{tabular}

Comparisons of bullying groups

The means and standard deviations for victims, bystanders, bullies, and bully-victims are shown in Table 2 .

Depression: The results support the hypothesis that victims were more likely to experience depression than non-victims, $t(78.95)=-2.82, p<.01, d=.46$. The mean of the victims $(M=15.66)$ approached the clinical threshold (16) as set forth by Radloff (1977; see Table 2). Those who identified as bystanders did not experience an increase 
in depression compared to non-bystanders, $t(121)=-.44, p$ $=.66$. Also, those who reported bullying others did not report higher levels of depression than non-bullies, $t$ (118) $=.53, p=.60$. Contrary to the hypothesis, those who were bully-victims did not report feeling more depressed than those who were in the non-bully-victim group, $t(123)=-$ $.78, p=.44$.

Table 2. Most frequent reasons why Bullying experience occurred

\begin{tabular}{|c|c|c|c|}
\hline Location & $\begin{array}{l}\text { Was } \\
\text { Victimized }\end{array}$ & $\begin{array}{l}\text { Observed } \\
\text { Bullying }\end{array}$ & $\begin{array}{l}\text { Bullied } \\
\text { Others }\end{array}$ \\
\hline Country of origin & $33.3 \%$ & $15.6 \%$ & $10.5 \%$ \\
\hline Being different & $25.5 \%$ & $52.1 \%$ & $31.6 \%$ \\
\hline Getting good grades & $23.5 \%$ & $12.5 \%$ & $13.2 \%$ \\
\hline wears & $21.6 \%$ & $41.7 \%$ & $21.1 \%$ \\
\hline Being fat & $21.6 \%$ & $53.1 \%$ & $30 \%$ \\
\hline Color of their skin & $19.6 \%$ & $20.8 \%$ & $16.2 \%$ \\
\hline Being a whimp & $17.7 \%$ & $49 \%$ & $32.5 \%$ \\
\hline Looking funny & $15.7 \%$ & $44.8 \%$ & $17.5 \%$ \\
\hline Being short & $15.7 \%$ & $32.3 \%$ & $26.3 \%$ \\
\hline $\begin{array}{l}\text { others } \\
\text { ons }\end{array}$ & $11.8 \%$ & $44.8 \%$ & $29 \%$ \\
\hline Being skinny & $9.8 \%$ & $11.5 \%$ & $8.1 \%$ \\
\hline Being gay & $9.8 \%$ & $20.8 \%$ & $18.4 \%$ \\
\hline Crying a lot & ---- & $37.5 \%$ & $29 \%$ \\
\hline Way the victim talks & --- & $34.4 \%$ & $29 \%$ \\
\hline Friends being weird & --- & $32.3 \%$ & $10 \%$ \\
\hline Getting angry often & --- & $22.9 \%$ & $18.4 \%$ \\
\hline $\begin{array}{l}\text { Being in special } \\
\text { education }\end{array}$ & ---- & $20.8 \%$ & $10.5 \%$ \\
\hline Getting bad grades & --- & $16.7 \%$ & $13.2 \%$ \\
\hline Being poor & & $13.5 \%$ & $13.2 \%$ \\
\hline Being disabled & & $12.5 \%$ & \\
\hline
\end{tabular}

Discrimination: Expectedly, victims experienced higher levels of discrimination than non-victims, $t(116)=-2.46$, $p=.015, d=.46$. Bystanders did not experience significantly more discrimination compared to nonbystanders, $t(121)=-.49, p=.62$. Those who identified as bullies, also, did not report higher levels of discrimination than non-bullies, $t(118)=-.71, p=.48$. Although those who were in the bully-victim group did not report higher levels of discrimination than the non-bullyvictim group, the results were in that direction, $t(123),=$ $1.53, p=.130$.

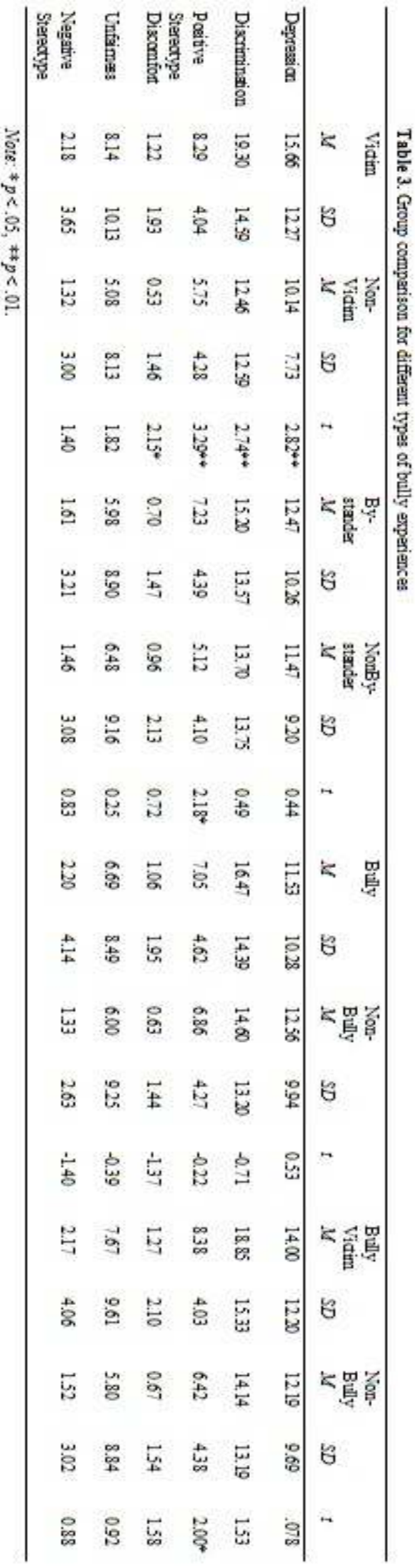


Positive Stereotype: Victims showed significant differences in being discriminated against via positive stereotyping than non-victims, $t(117)=-3.29, p<.01, d=$ .61. Bystanders also reported higher levels of witnessing discrimination via positive stereotyping, $t(121)=-2.18, p$ $=.03, d=.48$. Bullies did not experience higher levels of positive stereotyping $t(118)=-.22, p=.83$. However, bully-victims reported experiencing higher levels of positive stereotyping, $t(123)=-2.00, p=.048, d=.45$.

Discomfort: Victims showed significant differences in feeling discomfort as a result of being discriminated against compared to non-victims, $t(89.91)=-2.15, p=$ $.03, d=.28$. Neither bystanders $(t(121)=.72, p=.47)$, bullies $(t(58.69)=-1.23, p=.22)$, nor bully-victims $(t$ $(29.17)=-1.31, p=.20)$ reported experiencing higher levels of discomfort.

Unfairness: Victims report of unfairness was approaching an alpha level of $.05, t(117)=-1.82, p=.07$, but it was not significant. Bystanders $(t(121)=.25, p=$ $.80)$, bullies $(t(118)=-.39, p=.70)$, and bully-victims $(t$
$(123)=-.92, p=.36)$ also did not report higher levels of unfairness.

Negative Stereotype: None of the four groups, victims ( $t$ $(117)=-1.40, p=.17)$, bystanders $(t(121)=.22, p=.83)$, bullies $(t(118)=-1.40, p=.16)$, and bully-victims $(t(123)$ $=-.88, p=.38)$, reported higher levels of negative stereotype.).

Bullying experiences and their mental health outcomes

Path analyses with manifest variables were used to assess how well the bullying models presented by Shin et al. (2011) replicated for a younger school age population. All path analyses were undertaken with LISREL 8.80 . Model fit was assessed via several indices: $\chi^{2}$ - goodness-ffit-statistic, CFI, and RMSEA comparative fire measures, and the SRMR residual-based fit. These indices have differing strengths and weaknesses. The pattern of those indices was used to determine the overall adequacy of the model. Individual parameter estimates (direct effects, indirect effects, and correlations) were tested via t-tests.

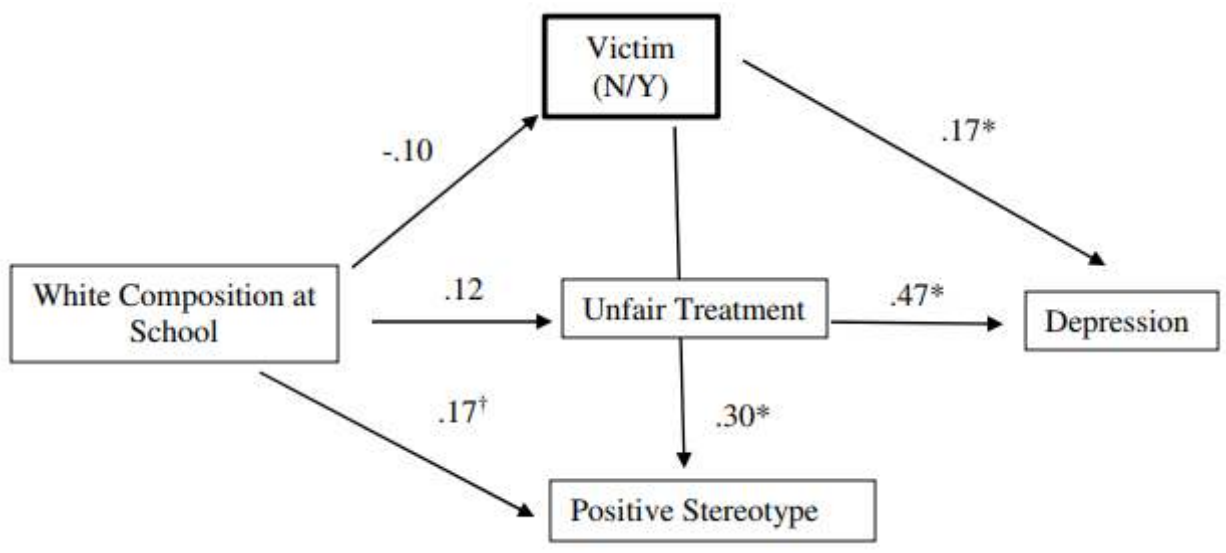

Figure 1. The victim model. Note: Standardized coefficients are shown $(\mathrm{N}=114) ;{ }^{*} p<.05 ; \dagger=p<.10$.

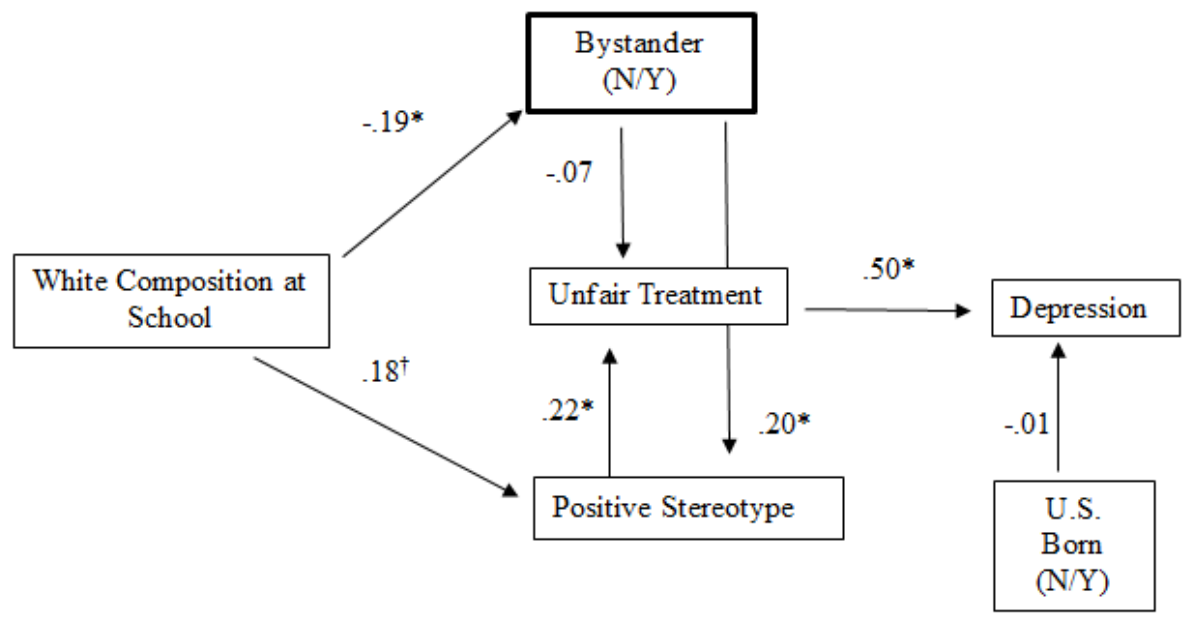

Figure 2. The bystander model. Note: Standardized coefficients are shown $(\mathrm{N}=118) ;{ }^{*} p<.05 ; \dagger=p<.10$. 


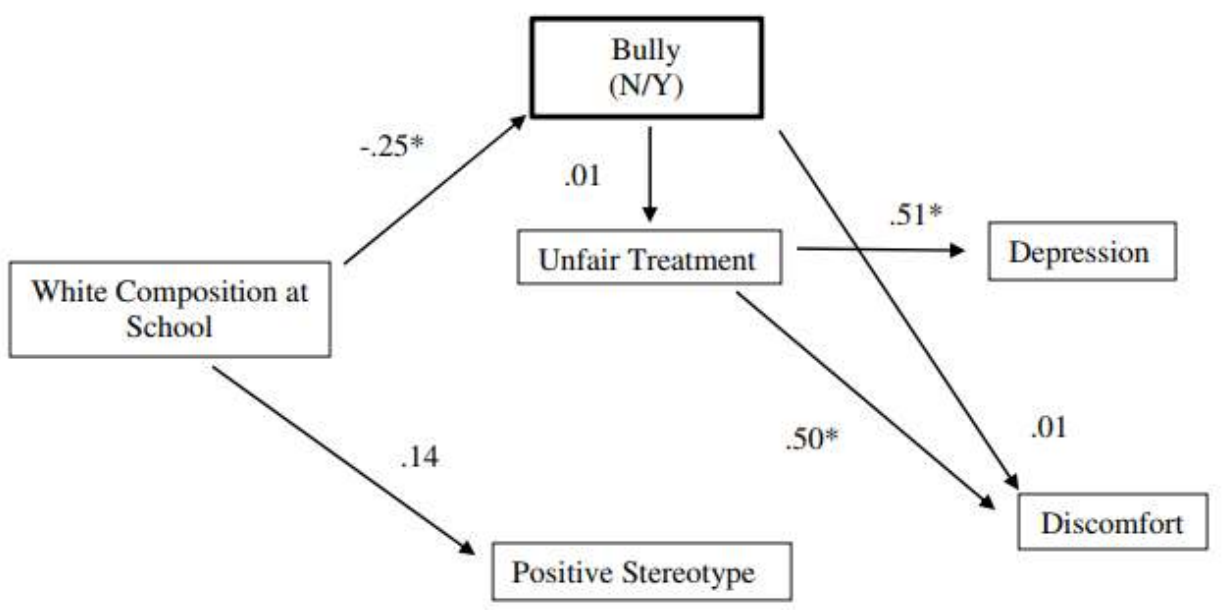

Figure 3. The bully model. Note: Standardized coefficients are shown $(\mathrm{N}=115) . * p<.05$.

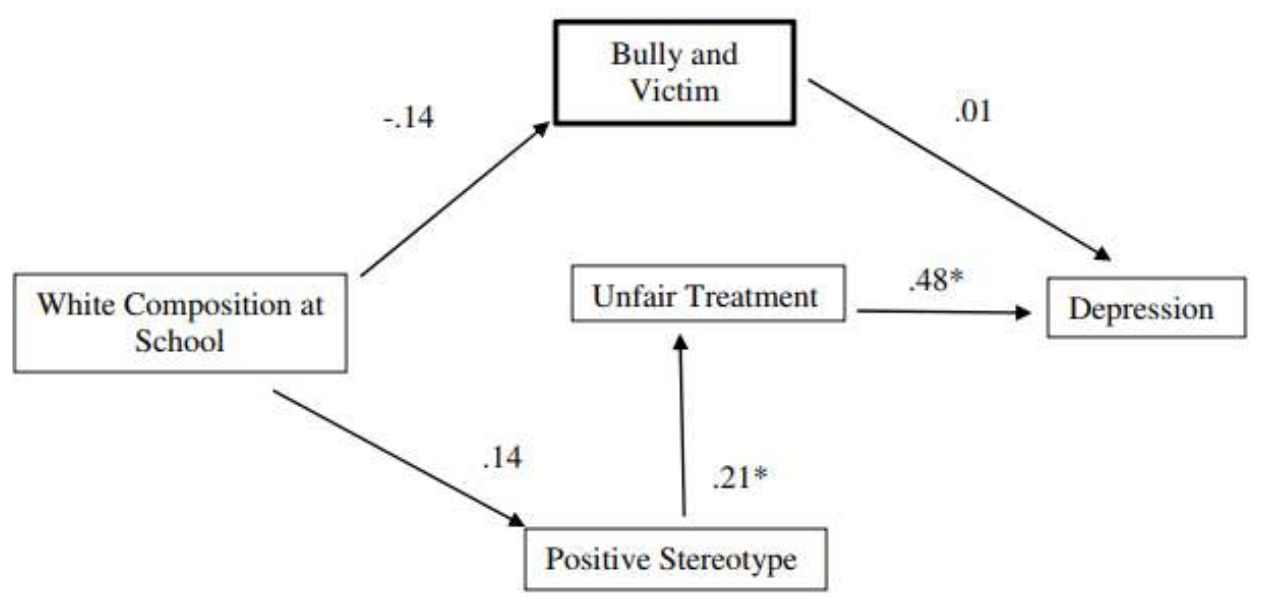

Figure 4. The bully-victim model. Note: Standardized coefficients are shown $(\mathrm{N}=120) .{ }^{*} p<.05$.

Victims: The results of the victims' model are presented in Figure 1. Model modification results indicated one additional path (victim to positive stereotype) was added to the path provided by Shin et al. (2011). This modified model was generally supported: $\chi^{2}(4, \mathrm{~N}=114)=7.75, p$ $=.10, R M S E A=.09$, and $C F I=.91$. Only the SRMR $(.07)$ indicated mediocre fit (values of .05 or less are indicative of well-fitting models). From Figure 1, it can be seen that two paths were not statistically significant, as compared to Shin et al. (2011). Specifically, the paths of white composition at school to victim and to unfair treatment were not replicated. Furthermore, there was no statistically significant indirect effect of white composition on depression. This non-significant indirect effect replicates the findings of Shin et al. (2011).

Bystander: The model for bystanders of bullying is represented in Figure 2. Modification indices supported that one additional path is supported that was not found from the model Shin et al. (2011) proposed (positive stereotype to unfair treatment). This model was supported for the junior high students: $\chi^{2}(7, \mathrm{~N}=118)=11.31, p=.13$ and RMSEA $=.07$. The CFI (.89) and SRMR (.06) suggested the model provided only a marginally adequate fit. Only two paths were not statically significant compared to Shin et al. (2011), bystander to unfair treatment and U.S. born to depression (see Figure 2). There was only one statistically significant indirect effect. Specifically, positive stereotype had a significant impact on depression $(.11, p<.05)$, which was mediated by unfair treatment.

Bully: The bully model is shown in Figure 3 . Modification indices support the inclusion of an additional path (unfair treatment to discomfort). This model was supported: $\chi^{2}(9, \mathrm{~N}=115)=10.83, p=.29, R M S E A=.04$, and $C F I=.97$. Only the $S R M R$ indicated marginal support (.07). There were no significant indirect effects. There were also three direct paths that were not supported by Shin et al. (2011; see Figure 3). Specifically, there was no relationship between white composition on positive stereotype, bullying on unfair treatment, and bullying on discomfort.

Bully-victims: In Figure 4, the results of the bullyvictim model are presented. Model modification indices supported the inclusion of an additional path (positive 
stereotype to unfair treatment). This model was supported: $\chi^{2}(5, \mathrm{~N}=120)=7.31, p=.20, R M S E A=.06$, and $C F I=.93$. Again, the $S R M R$ index only indicated marginal support (.06). Three direct paths were non-significant as compared to Shin et al. (2011; see Figure 4). The paths that were not supported are: white composition at school on positive stereotype and being a bully-victim, as well as being a bully-victim on depression. There were no significant indirect effects for the white composition of the school on student depression. However, there was a statistically significant indirect effect of positive stereotype on depression $(.10, \mathrm{p}<.05)$, that was mediated by unfair treatment.

\section{Discussion}

As mentioned before, the bullying experience affected everyone involved, victims, bullies, and bystanders. There was an alarmingly high victim rate of approximately $42.9 \%$ among the Korean-American junior high school students who participated in the study. That means that more than two of every five students are being bullied, which is very high. The majority of students took part in the bullying experience as bystanders $(72.8 \%)$ and are still at risk for developing negative side effects of bullying (Rivers et al., 2009).

Previous research anticipated the prevalence rate of bullies to be within 5 to $13 \%$ (Nansel et al., 2001; Perkins et al., 2011; Peskin et al., 2006); however, this study found that the prevalence rate of a Korean-American being a bully was $(32.5 \%)$. This elevated prevalence rate for Korean-Americans is consistent with Shin et al. (2011) for Korean-Americans (31.5\%); however, other research indicates that Asian-Americans are less likely to be bullies (Moran et al., 1993). Based on this study and Shin et al. (2011), Korean-Americans are two to six times more likely to be a bully than other ethnicities. Future research is needed to confirm these results.

As hypothesized based upon the literature, victims reported higher levels of depression $(M=15.66)$, which approached the clinically significant level of 16 , as determined by the instrument. However, the hypotheses for bullies and bully-victims reporting higher rates of depression were not supported. This could be because the bullies and bully-victims were ashamed to report depression, as it is looked down upon in the AsianAmerican community (Gary, 2005; Leong \& Lau, 2001) and the bullies and bully-victims may try to keep up their strong and imperturbable façade.

In this study, discrimination was examined as a whole and by its individual components. Discrimination was broken down to unfair treatment, positive stereotype, negative stereotype, and discomfort, based upon Shin et al. (2011). As predicted, victims experienced more discrimination than non-victims. Victims thought they were discriminated against via positive stereotyping and general discomfort. Bystanders saw discrimination occur via positive stereotyping, and bully-victims thought they were discriminated against via positive stereotyping. Building the results upon one another, it appears that victims are more likely to suffer from depression due to discrimination, specifically positive stereotyping. Asian American individuals are often seen as model citizens, in that they do not get into trouble often and do well in school. This positive stereotyping could actually be doing more harm than good.
Figure 1 displays the path analysis for the victim model. Being a victim and unfair treatment are related to feeling depressed. The model also shows that white composition of the school directly affected victims thinking they were discriminated against via positive stereotyping. However, white composition of the school did not significantly affect depression, coinciding with the results from Shin et al.'s (2011).

Figure 2 is the path analysis for the bystander model. Unfair treatment directly affects feeling depressed for bystanders. White composition of the school directly affected being a bystander and positive stereotype. Being a bystander directly affected positive stereotype. In turn, positive stereotype directly affected unfair treatment and it indirectly affected depression. The direct effect on unfair treatment and the indirect effect on depression were not found in Shin et al. (2011). It appears that positive stereotyping plays a bigger role in middle school than in high school. A common stereotype of Korean-Americans is that they do well in school. The fact that positive stereotyping plays a bigger role in middle school than high school could be because middle school is when academic achievement begins to play an important role in the students' lives. This may highlight the Korean-American's excellence, forcing them into the social spotlight.

Figure 3 is the path analysis for the bully model. White composition of the school negatively impacted being a bully. As white composition decreased, bullies increased. This is not a surprise considering the high prevalence rate of Korean-American bullies. Just as in the past two models, unfair treatment is related to depression. Unfair treatment also affects discomfort. As discussed earlier, an unsupported finding was that being a bully would have an effect on depression.

Figure 4 is the path analysis for the bully-victim model. Similarly to the bystander model, positive stereotyping directly affected unfair treatment and indirectly affected depression. Unfair treatment also affected depression. As mentioned earlier, an unsupported finding was that being a bully-victim would affect depression, which was found in Shin et al. (2011). Shin et al. (2011) also found that the white composition at school affected bully-victims and positive stereotyping.

Looking at these models as a whole, white composition affected the bullying variable for bystander and had a negative effect on bullies. Unfair treatment affected depression, as in Shin et al. (2011). Positive stereotyping had more impact in this study for middle school students than for high school students (Shin et al., 2011). In the bystander and bully-victim models, positive stereotyping affected unfair treatment and indirectly affected depression. This could be because a lot of pressure is put on these individuals by their culture and parents to perform well. The pressure by their parents may have an additive effect with stereotyping, further increasing the depression. The bystanders may not be able to handle the pressure and thus become depressed. As in Shin et al. (2011), no evidence was found for an indirect effect of white composition on depression.

Two of the biggest factors that are related to depression are being treated unfairly and positive stereotyping. These findings show that the middle school-aged KoreanAmericans experience depression as a result of being a victim of bullying and being treated unfairly, just as the high school-aged Korean-Americans do. These path analyses for middle school and high school (Shin et al., 2011), can be used to create culturally and age appropriate 
intervention and prevention models. The fact that positive stereotyping appears to be much more of a factor in the middle-school Korean-Americans, can help individuals tailor the bullying prevention and intervention plans toward limiting positive stereotyping. As such, intervention and prevention strategies could include educating staff and students about the dangers of positive stereotyping.

While these results are insightful, there are a few limitations to the study. The participants were from the New York and New Jersey school districts. Many KoreanAmericans living in New York and New Jersey have a large Korean-American community surrounding them, which could moderate the effects of bullies and acculturation. This could affect the generalizability of the results.

It was also difficult to assess whether the prevalence of victims and bullies for Korean-Americans were high. There were no other ethnic groups in the study to compare the data. Future researchers should look at the prevalence rates across different ethnic groups

Future research should also focus on the long-term effects of bullying-induced depression and discrimination and how that plays a role for Korean-Americans. It is possible that minorities are at a higher risk for bullying, possibly intensifying the long-term effects.

\section{References}

Aldwin, C. \& Greenberger, E. (1987). Cultural differences in the predictors of depression. American Journal of Community Psychology, 15, 789-813.

Berkowitz, R., \& Benbenishty, R. (2012). Perceptions of teachers' support, safety, and absence from school because of fear among victims, bullies, and bully-victims. American Journal of Orthopsychiatry, 82(1), 67-74

Bonanno, R. A., \& Hymel, S. (2010). Beyond hurt feelings: Investigating why some victims of bullying are at greater risk for suicidal ideation. Merrill-Palmer Quarterly, 56(3), 420-440.

Boulton, M. J. (1995). Parents of bully/victim problems in mixed race groups of children. Social Development, 4(3), 277-293.

Choi, G. (1997). Acculturative stress, social support, and depression in Korean American families. Journal of Family Social Work, 2, 81-97.

Cook, C. R., Williams, K. R., Guerra, N. G., Kim, T. E., \& Sadek, S. (2010). Predictors of bullying and victimization in childhood and adolescence: A meta-analytic investigation. School Psychology Quarterly, 25(2), 65-83.

Espelage, D. L., \& Holt, M. K. (2001). Bullying and victimization during early adolescence: Peer influences and psychosocial correlates. Journal of Emotional Abuse, 2(2-3), 123-142.

Espelage, D. L., \& Swearer, S. M. (2003). Research on School Bullying and Victimization: What Have We Learned and Where Do We Go From Here? School Psychology Review, 32(3), 365-383.

Gary, F. A. (2005). Stigma: Barrier to mental health care among ethnic minorities. Issues in Mental Health Nursing, 26(10), 979-999.

Gini, G., \& Pozzoli, T. (2013). Bullied children and psychosomatic problems: A meta-analysis. Pediatrics, 132(4), 720-729.

Graham, S., \& Juvonen, J. (1998a). A social-cognitive perspective on peer aggression and victimization. In $\mathrm{R}$. Vasta (Ed.), Annals of child development (pp.23-70). London, U.K.: Jessica Kingsley.
Grossman, M. J. (2005). Discrimination distress among Asian American adolescents.Unpublished doctoral dissertation, Boston College, Boston.

Hanish, L. D., \& Guerra, N. G. (2000). Predictors of peer victimization among urban youth. Social Development, 9(4), 521-543.

Hovey, J. D., Kim, S. E., \& Seligman, L. D. (2006). The Influences of Cultural Values, Ethnic Identity, and Language Use on the Mental Health of Korean American College Students. The Journal of Psychology: Interdisciplinary and Applied, 140(5), 499-511.

Juvonen, J., \& Graham, S. (2014). Bullying in schools: The power of bullies and the plight of victims. Annual Review of Psychology, 65, 159-185.

Juvonen, J., Graham, S., \& Schuster, M. A. (2003). Bullying among your adolescents: The strong, the weak, and the troubled. Pediatrics, 112, 1231-1237.

Juvonen, J., Nishina, A., \& Graham, S. (2000). Peer harassment, psychological adjustment, and school functioning in early adolescence. Journal of Educational Psychology, 92(2), 349-359.

Kaltiala-Heino, R., Rimpelä, M., Marttunen, M., Rimpelä, A., \& Rantanen, P. (1999). Bullying, depression, and suicidal ideation in Finnish adolescents: School survey. British Medical Journal, 319, 348-351.

Kaltiala-Heino, R., Rimpelä, M., Rantanen, P., \& Rimpelä, A. (2000). Bullying at school - an indicator of adolescents at risk for mental disorders. Journal of Adolescence, 23(6), 661-674.

Kessel Schneider, S., O'Donnell, L., Stueve, A., \& Coulter, R. S. (2012). Cyberbullying, school bullying, and psychological distress: A regional census of high school students. American Journal of Public Health, 102(1), 171177.

Kim, E., \& Cain, K. C. (2008). Korean American adolescent depression and parenting. Journal of Child and Adolescent Psychiatric Nursing, 21(2), 105-115.

Knack, J. M., Jensen-Campbell, L. A., \& Baum, A. (2011). Worse than sticks and stones? Bullying is associated with altered HPA axis functioning and poorer health. Brain and Cognition, 77(2), 183-190.

Kumpulainen, K., \& Räsänen, E. (2000). Children involved in bullying at elementary school age: Their psychiatric symptoms and deviance in adolescence: An epidemiological sample. Child Abuse \& Neglect, 24(12), 1567-1577

Kumpulainen, K., Räsänen, E., \& Henttonen, I. (1999). Children involved in bullying: Psychological disturbance and the persistence of the involvement. Child Abuse \& Neglect, 23(12), 1253-1262.

Kumpulainen, K., Räsänen, E., Henttonen, I., Almqvist, F., Kresanov, K., Linna, S., \& ... Tamminen, T. (1998). Bullying and psychiatric symptoms among elementary school-age children. Child Abuse \& Neglect, 22(7), 705 717.

Kuo, H. K., \& Tsai, Y. (1986). Social networking, hardiness and immigrant's mental health. Journal of Health and Social Behavior, 27, 133-149.

Kuo, W. H. (1984). Prevalence of depression among AsianAmericans. Journal of Nervous and Mental Disease. 172. 449-457.

Lee, E. (1997). Working with Asian Americans: A guide for clinicians. New York: Guilford Press

Leong, F. L., \& Lau, A. L. (2001). Barriers to providing effective mental health services to Asian Americans. Mental Health Services Research, 3(4), 201214.

Liang, B., Grossman, J. M., \& Deguchi, M. (2007). Chinese American middle school youths' experiences of discrimination and stereotyping. Qualitative Research in Psychology, 4(1-2), 187-205. 
Mayers, S. (2013, April 28). Cyber Bullying Quotes. Retrieved May 20, 2015, from http://nobullying.com/cyber-bullyingquotes.

Moran, S., Smith, P. K., Thompson, D., \& Whitney, I. (1993). Ethnic differences in experiences of bullying: Asian and White children. British Journal of Educational Psychology, 63(3), 431-440.

Mouttapa, M., Valente, T., Gallaher, P., Rohrbach, L. A., \& Unger, J. B. (2004). Social network predictors of bullying and victimization. Adolescence, 39(154), 315-335.

Nansel, T. R., Overpeck, M., Pilla, R. S., Ruan, W. J., SimonsMorton, B., \& Scheidt, P. (2001). Bullying behaviors among US youth: Prevalence and association with psychosocial adjustment. JAMA: Journal of the American Medical Association, 285, 2094-2100.

New Jersey Department of Education. (2008). 2007-2008 School report card. Retrieved from Trenton, New Jersey: Author. http://education.state.nj.us/rc/ rc08/menu/01.html.

NYSTART. (2007). New York state school and district report cards for school year 2006-2007. Retrieved from. Albany, NY: Author. https://www.nystart.gov/publicweb/Home. do?year-2007.

Noh, S., Avison, W. R., \& Kaspar, V. (1992). Depressive symptoms among Korean immigrants: Assessment of a translation of the Center for Epidemiologic StudiesDepression Scale. Psychological Assessment, 4(1), 84-91.

O'Connell, P., Pepler, D., \& Craig, W. (1999). Peer involvement in bullying: Insights and challenges for intervention. Journal of Adolescence, 22(4), 437-452

Oh, Y. Koeske, G. R, \& Sales, E. (2002). Acculturation, stress, and depressive symptoms among Korean immigrants in the United States. Journal of Social Psychology, 142, 511526.

Olweus, D. (1993). Bullying at school. What we know and what we can do. Cambridge, MA: Blackwell.

Perkins, H. W., Craig, D. W., \& Perkins, J. M. (2011). Using social norms to reduce bullying: A research intervention among adolescents in five middle schools. Group Processes \& Intergroup Relations, 14(5), 703-722.

Peskin, M. F., Tortolero, S. R., \& Markham, C. M. (2006). Bullying and victimization among Black and Hispanic adolescents. Adolescence, 41(163), 467-484.

Peskin, M. F., Tortolero, S. R., Markham, C. M., Addy, R. C., \& Baumler, E. R. (2007). Bullying and victimization and internalizing symptoms among low-income Black and Hispanic students. Journal of Adolescent Health, 40(4), 372-375.

Qin, D. B., Way, N., \& Mukherjee, P. (2008). The other side of the model minority story: The familial and peer challenges faced by Chinese American adolescents. Youth \& Society, 39(4), 480-506.

Radloff, L. S. (1977). The CES-D scale: a self-report depression scale for research in the general population. Applied Psychological Measurement, 1, 385-401.

Rhee, S. (1996). Effective social work practice with Korean immigrant families. Journal of Multicultural Social Work, 4(1), 49-61.

Rivers, I., Poteat, V. P., Noret, N., \& Ashurst, N. (2009). Observing bullying at school: The mental health implications of witness status. School Psychology Quarterly, 24(4), 211-223.
Roland, E. (2002). Bullying, depressive symptoms, and suicidal thoughts. Educational Research, 44, 55-67.

Salmivalli, C., Lagerspetz, K., Björkqvist, K., Österman, K., and Kaukianinen, A. (1996). Bullying as a group process: Participant roles and their relations to social status within the group. Aggressive Behavior, 22, 1-15.

Shin, K. R. (1994). Psychosocial predictors of depressive symptoms in Korean-American women in New York City. Women and Health, 21, 73-82.

Shin, J. Y., D’Antonio, E., Son, H., Kim, S., \& Park, Y. (2011). Bullying and discrimination experiences among Korean-American adolescents. Journal of Adolescence, 34(5), 873-883.

Shrake, E. K., \& Rhee, S. (2004). Ethnic Identity as a Predictor of Problem Behaviors Among Korean American Adolescents. Adolescence, 39(155), 601-622.

Smith, P. K., Talamelli, L., Cowie, H., Naylor, P., \& Chauhan, P. (2004). Profiles of non-victims, escaped victims, continuing victims and new victims of school bullying. British Journal of Educational Psychology, 74(4), 565-581

Sourander, A., Helstelä, L., Ristkari, T., Ikäheimo, K., Helenius, H., \& Piha, J. (2001). Child and adolescent mental health service use in Finland. Social Psychiatry and Psychiatric Epidemiology, 36(6), 294-298.

Srabstein, J., \& Piazza, T. (2013). Public health, safety and educational risks associated with bullying behaviors in American adolescents. In J. C. Srabstein, J. Merrick, J. C. Srabstein, J. Merrick (Eds.), Bullying: A public health concern (pp. 223-232). Hauppauge, NY, US: Nova Science Publishers.

Sue, S. (1994). Mental health. In N. Zane, D.T. Takeuchi, \& K. Young (Eds.), Confronting critical health issues of Asian and Pacific Islander Americans (pp266-288). Newbury Park, CA: Sage.

Swearer, S. M. (2005). The bully survey. Unpublished questionnaire. University of Lincoln-Nebraska.

Swearer, S. M., Song, S. Y., Cary, P. T., Eagle, J. W., \& Mickelson, W. T. (2001). Psychosocial correlates in bullying and victimization: The relationship between depression, anxiety, and bully/victim status. Journal of Emotional Abuse, 2(2-3), 95-121.

Uba, Laura (1994). Asian Americans: Personality patterns, identity and mental health. New York, NY: Guilford Press.

U.S. Department of Education. (1999). 1999 Annual report on school safety. Retrieved from. Washington, D.C.: U.S. Dept of Education. http://files.eric.ed.gov/fulltext/ ED436860.pdf .

Way, N. (1997). The perceived ethnic and racial discrimination scale. Unpublished Manuscript. New York University.

Ying, Y. W. (1998). Strengthening intergenerational/ intercultural ties in migrant families: A new intervention for parents. Journal of Community Psychology, 27(1), 8996. 